\title{
marges Marges
}

revue d'art contemporain Revue d'art contemporain

\section{« Hommage à Philippe Thomas et autres œuvres ",} augmenté de «L'ombre du jaseur (d'après Feux Pâles)»

Genève, Musée d'art moderne et contemporain, 12 février - 18 mai 2014

Émeline Jaret

\section{OpenEdition}

Journals

Édition électronique

URL : http://journals.openedition.org/marges/952

DOI : $10.4000 /$ marges.952

ISSN : 2416-8742

\section{Éditeur}

Presses universitaires de Vincennes

\section{Édition imprimée}

Date de publication : 1 octobre 2014

Pagination : 152-153

ISBN : 978-2-84292-415-7

ISSN : $1767-7114$

\section{Référence électronique}

Émeline Jaret, « «Hommage à Philippe Thomas et autres œuvres », augmenté de «L'ombre du jaseur (d'après Feux Pâles) » », Marges [En ligne], 19 | 2014, mis en ligne le 01 octobre 2014, consulté le 25 septembre 2020. URL : http://journals.openedition.org/marges/952 ; DOI : https://doi.org/10.4000/ marges.952 


\section{«Hommage à Philippe Thomas et autres œuvres », augmenté de «L'ombre du jaseur (d'après Feux Pâles) »}

Genève, Musée d'art moderne et contemporain, 12 février - 18 mai 2014

Début 2014, le travail de l'artiste français Philippe Thomas (1951-1995) bénéficie d'une importante exposition à visée rétrospective, organisée par le Musée d'art moderne et contemporain (Mamco) de Genève. Pour l'institution, qui fêtait cette année ses vingt ans d'existence, le choix de montrer l'œuvre de cet artiste possède une valeur mémorielle, en même temps que cela concrétise un projet pensé depuis de nombreuses années, témoin d'une histoire longue entre elle et l'artiste. En effet, c'est au Mamco que Philippe Thomas a vendu et déposé son agence en 1994 quand il a décidé de clôturer son histoire - readymades belong to everyone ${ }^{\circledR}$ ayant été fondée à New York en 1987. La présentation du stock room de readymades belong to everyone ${ }^{\circledR}$ avait d'ailleurs occupé l'espace de l'institution genevoise pendant les premiers mois de son existence. L'exposition, qui s'intitule " Hommage à Philippe Thomas et autres œuvres » en référence à l'anthologie des écrits de Philippe Thomas publiée également par le Mamco en 1999 (Sur un lieu commun et autres textes), s'articule autour de deux ensembles: le premier se veut une rétrospective des œuvres de l'artiste de 1981 à 1994, réparties sur plusieurs étages du musée; le second, qui en occupe le dernier niveau, réactive l'exposition «Feux Pâles» organisée par Philippe Thomas en 1990 au CAPC de Bordeaux.

Ce dernier constitue le cœur du projet initial voulu par Christian Bernard, le directeur du Mamco. Intitulé « L'Ombre du jaseur (d'après Feux Pâles) », il reprend le jeu de la référence au roman de Nabokov (Feu Pâle, 1961) dont Philippe Thomas avait emprunté le titre en le pluralisant, et cite le premier vers du poème de John Shade: "C'était moi l'ombre du jaseur tué / Par l'azur trompeur de la vitre. ». L'exposition de 1990, commandée par le CAPC et pensée intégralement par Philippe 
Thomas, était combinée avec l'édition d'un catalogue. Le dialogue entre ces deux éléments proposait une relecture de l'histoire de l'art tout en retraçant l'histoire du musée, des Wunderkammern du XVIe siècle jusqu'aux années 1960. Le dispositif initial conçu par Philippe Thomas, exposition-œuvre dont les allers-retours entre l'exposition même et le catalogue, les jeux instaurés entre les dizaines de signatures qui les peuplent, les multiples contaminations entre espaces réel et fictionnel, et l'entrée d'une institution telle que le CAPC comme signataire de l'agence, permettaient au projet global de passer un cap fondamental. Une re-création à l'identique étant impossible, l'exposition de 2014 tente d'en fournir une nouvelle interprétation en étendant cette histoire au postmodernisme et, pour pallier au manque de certaines des œuvres montrées à Bordeaux, propose des équivalents historiques ou formels de manière à respecter au mieux le projet thomassien en conservant la cohérence des thématiques de chacune des douze salles.

Exposition dans l'exposition, elle complète l'« Hommage à Philippe Thomas et autres œuvres » répartie sur les trois autres étages du musée par la présence de certaines œuvres réalisées par l'artiste au sein de l'agence et avant celle-ci. Elle tente d'offrir un panorama aussi complet que possible de ses œuvres, depuis le manuscrit trouvé, daté de 1981 jusqu'aux événements qui ont contribué à la fermeture de l'agence en 1993 et 1994 . L'exposition s'organise par ensembles chronologiques, respectant la narration construite par l'artiste et les séries qu'il a constituées: une accumulation de codes-barres occupe le large couloir central du second étage qui dessert des salles consacrées aux séries photographiques Insights ou Übergänge, quand d'autres salles reproduisent des expositions de l'agence comme sa participation à « Art \&
Pub » en 1991 au Centre Pompidou, ou encore rassemblent les œuvres d'une autre exposition telle que celle qui eut lieu en 1992 à la galerie Massimo Minini, à Brescia. Le tout est complété par une sélection d'archives provenant du Fonds Philippe Thomas, conservé à la bibliothèque Kandinsky du Centre Pompidou. En cela, le titre de l'exposition dit vrai : il s'agit d'un bel hommage à Philippe Thomas, offrant un accrochage de qualité, près de quatorze ans après ceux du Musée d'art contemporain de Barcelone et du Magasin de Grenoble. La plupart des œuvres de Philippe Thomas sont rarement visibles et son projet, complexe et difficilement accessible, nécessite une vue d'ensemble pour apprécier sa cohérence. Mais cette exposition pose tout de même la question de la valeur d'un tel accrochage, qui se borne à dérouler la chronologie des événements de 1981 à 1994 - sans être toutefois exhaustif - quand il semble que, vingt ans après le décès de l'artiste, un regard critique sur la dimension historique de cette œuvre n'a toujours pas été posé. Ainsi que le dit lui-même Philippe Thomas dans un entretien inédit de 1995 avec Stéphane Wargnier, l'intérêt de ce travail ne se situe pas exactement dans les événements qui le définissent, mais plutôt dans les conditions de réalisation de ceux-ci. Si notre rôle aujourd'hui est de mettre l'accent sur cela, il est certain que l'exposition du Mamco ne s'y attache pas. L'absence de catalogue, voire d'un appareil critique et pédagogique suffisant autour de l'exposition, tend à renforcer ce manque de problématisation et de contextualisation; même si ce manque a été partiellement combler par la récente livraison de la revue Retour d'y voir $\left(\mathrm{n}^{\circ} 5\right.$, « Retraits de l'artiste en Philippe Thomas », juin 2012), consacrée intégralement à Philippe Thomas.

\section{Emeline Jaret}

